or diameter. An elliptical segment which guides the in sizes from $2 \frac{1}{2}$ to 24 inches, and another corresponding segment is inserted into the machine for cutting for boiler or machine shops, and a rivet head-cutting machine is built which is very handy for the boiler shop. (To be concluded.)

\section{TO DETERMINE SIZE OF GAS AND OIL} ENGINE CYLINDERS.

\section{By Newton Wright.}

THE determination of the size of a gas engine cylin der from the heating value of the fuel, and the presimpractical, as the losses due to incomplete combus tion, cooling effect of jacket, and incomplete expansion, cannot be estimated with any great degree of accuracy. The size is most conveniently determined from the The size is most conveniently determined from the known fuel consumption of engines of similar power
and type, provided the ratio of air to gas is also known. The formulas given in this article will aid in determining the size required, in this manner. In the formulas given the notation used is as follows:

$d=$ diameter of cylinder in inches,

$s=$ stroke in inches,

$n=$ revolutions per minute

$H=$ brake horse-power per cylinder,

$w=$ pounds of oil per brake horse-power hour,

$r=$ ratio of air to gas or vapor,

$r_{1}=$ ratio of air and products of combustion (in clearance space) to gas or vapor,

$k=$ ratio of total capacity of cylinder to piston dis placement,

$V=$ piston displacement per stroke in cubic inches,

$V_{1}=$ piston displacement in cubic inches per brake horse-power

$v=$ clearance volume in cubic inches,

$m=$ ratio of diameter to stroke.

One pound of heavy oil gives about 12 cubic feet of consequently, in applying the following formula for the ratio of air to gas or vapor, to oil engines, $12 w$ and $6 w$, respectively, are substituted for $c$. The value of the ratio $r$ is expressed by the formula

$$
r=\frac{d^{2} s n}{c h \times 72}-1
$$

The ratio $r$ varies from 2 to 3.3 for producer gas, from 7 to 12 for lighting gas, from 27 to 40 for vapor of heavy oil, and from 36 to 52 for the vapor of light lies between the two figures given, but is generally nearer tho lower than the higher. Perhaps the average figures would be with producer gas, 2.4; lighting gas, figures would be with producer gas, 2.4 ; lighting gas, 9 ; heavy oil, $30 ;$ : and light oil, 40 . In the last two
instances, this value of the ratio would make 360 cubic instances, this value of the ratio would make 360 cubic
feet of air per pound of heavy oil, and 240 cubic feet of air per pound of light oil.

The value of the ratio of air and products of combustion (in clearance space) to gas or vapor is expressed by the formula: cutting nozzle is applied to the cutting of oval holes round or square holes. This machine is very handy sure caused by the theoretical rise of temperature, is

$c=$ cubic feet of gas per brake horse-power hour, vapor, and one pound of light oil about 6 cubic feet; oil. With the most economical engines the value of $r$

The value of $k$ is higher than it apparently would be, as the heating of the air following the compression causes the pressure to rise in a greater ratio than that due to the actual compression. When mean are taken to clear the cylinder of the products of combustion, as is usual with engines working on producer gas, then $r_{1}$ will equal the ratio of pure air to gas.

The value of the piston displacement per stroke, in cubic inches, $V$, is expressed by the formula:

$$
v=\frac{H c(r+1) 57.6}{n}
$$

The relation between the diameter of the cylinder

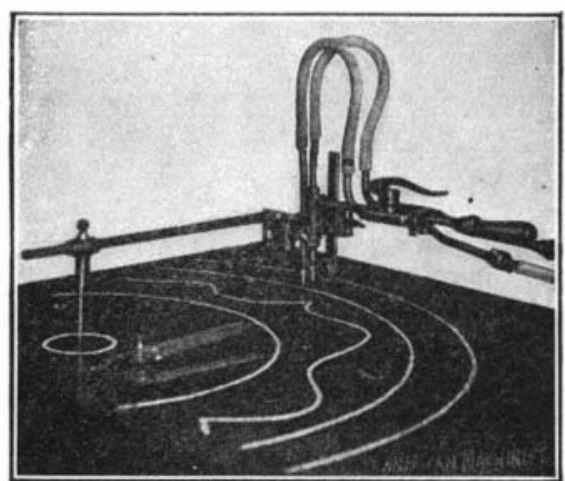

Fig. 11, ANOTHEI MACHINE CUTting RegUlar AND IRREGULAR CURVES.

and the other quantities affecting it, is expressed by the formula:

$$
d=4.2 \sqrt{m} \sqrt[3]{\frac{11 c r+1)}{n}}
$$

The ratio of the diameter to the stroke $m$ equals, of course, $\frac{d}{,}$, or $d=s m$. From the formula given it will $s$

be seen that if the length of stroke is given, the power of the engine will be proportional to the square of the diameter; but if the ratio of the diameter to the stroke is given, the power will be proportiona to the cube of the diameter. Table II gives the usua values of $m$ employed.

The clearance volume is determined by the formula, $v=V(k-1)=d^{2} s \times 0.7854(k-1)$

The total volume of the cylinder equals $v+v=v k$.

Table II. Common Values for Quantities Entering In

\begin{tabular}{|c|c|c|c|c|c|}
\hline Fuel Used. & $I I$ & $c$ or $w$ & $n$ & $m$ & $V_{1}$ \\
\hline roducer gas. . & $\begin{array}{c}20-50 \\
50-100 \\
\text { over } 100\end{array}$ & $\begin{array}{l}8.5 \\
80 \\
75\end{array}$ & $\begin{array}{l}170 \\
160 \\
150\end{array}$ & $\begin{array}{l}0.6 \\
0.7 \\
0.9\end{array}$ & $\begin{array}{l}100 \\
100 \\
100\end{array}$ \\
\hline ighting gas .... & $\begin{array}{r}\text { to } 5 \\
5-20 \\
20-50\end{array}$ & $\begin{array}{l}30 \\
25 \\
20\end{array}$ & $\begin{array}{l}300 \\
220 \\
170\end{array}$ & $\begin{array}{l}0.5 \\
0.5 \\
0.6\end{array}$ & $\begin{array}{l}60 \\
66 \\
70\end{array}$ \\
\hline
\end{tabular}
Calculations of Size of Gas and Oil Engine Cylinders.

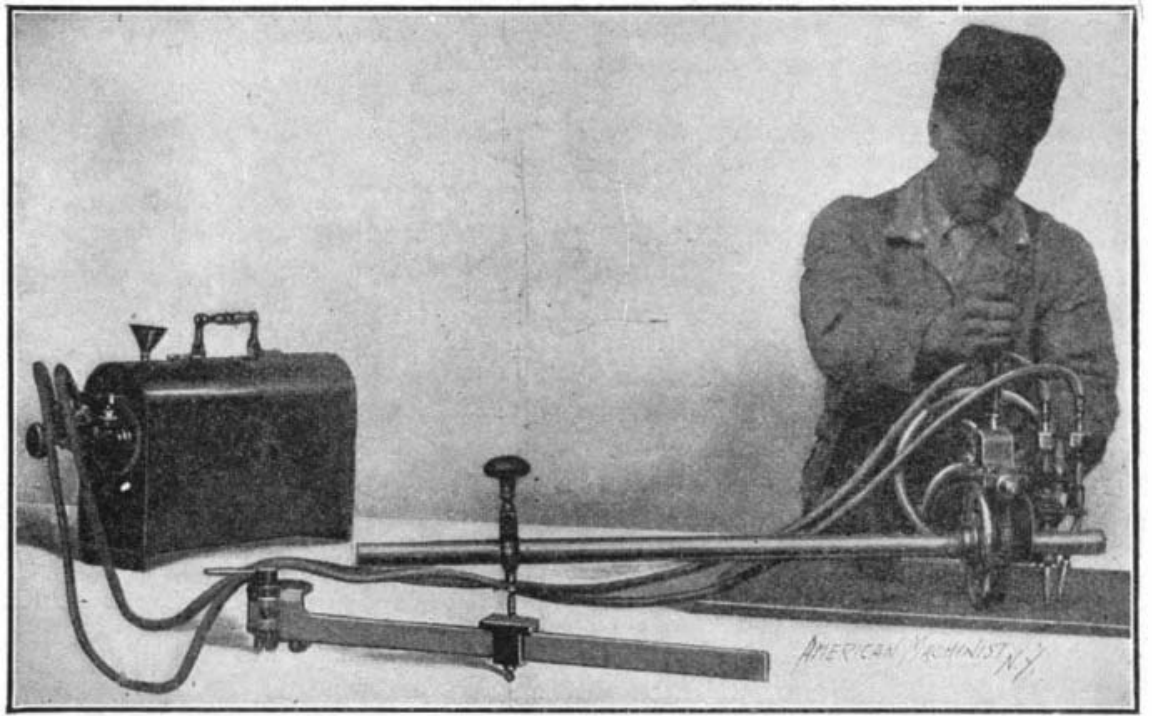

FIG. 10, - MACHINE FOR REGULAR OR IRREGULAR CIRCULAR CU'TTING. OXHYDRIC PROCESS OF CUTTING METALS.

$$
r_{1}=\frac{d^{2} s n k}{c H \times 72}-1
$$

The ratio $k$ of total capacity of cylinder to piston

\begin{tabular}{|c|c|c|}
\hline $\begin{array}{l}\text { Absolute } \\
\text { Compression } \\
\text { in Pounds per } \\
\text { square Inch. }\end{array}$ & 76 & $\begin{array}{l}\text { Absolute } \\
\text { Compression } \\
\text { in Pounds per } \\
\text { Square Inch. }\end{array}$ \\
\hline 30 & 2.65 & 75 \\
\hline 45 & 1.86 & 90 \\
\hline 60 & 1.58 & 105 \\
\hline
\end{tabular}
displacement is given in Table I.

Table I. Ratio of Total Cylinder Capacity to Piston Displacement. light oil engines the piston speed is seldom less than 650 feet per minute, even in the smallest sizes, and more in the larger.

Assuming a consumption of 80 cubic feet of producer gas per brake horse-power, 25 cubic feet of lighting gas, 0.9 pound of heavy oil and 0.75 pound of light oil, and taking the average values of $r$ as given in the first part of this article, the following formula may be employed for finding the tiameter of the cylinders, if the ratio between the diameter and the length of stroke is giren.

$$
d=f \sqrt[3]{m} \sqrt[3]{\frac{\hat{H}}{n}}=\frac{f \sqrt[3]{\bar{m}}}{\sqrt[3]{\frac{n}{H}}}
$$

In this formula $f$ is a coefficient which equals 27.2 for producer gas, 26.4 for lighting gas, 29 for heavy oil, and 24 for light oil. At ordinary speed $H$ would equal, approximately, $\frac{d^{2}}{5}$ for producer gas, $\frac{d^{2}}{4}$ for lighting gas, $\frac{d^{2}}{6}$ for heavy oil, and $\frac{d^{2}}{4}$ for light oil. These formulas, however, will not hold good for very small engines, say under 10 horse-power, except for ihose using light oil. $\bullet$

The heating value of the fuel is usually as follows: Producer gas, 150 B. T. U. per cubic foot; lighting gas, 660 B. T. U. per cubic foot; heavy oil (specific gravity about 0.88$), 20,000$ B. T. U. per pound; light oil (specific gravity about 0.69 ), 28,000 B. T. U. per pound.

As has been mentioned before, one pound of heavy oil gives 12 cubic feet of vapor, and one pound of light oil about 6 cubic feet, so that the heating value per cubic foot of vapor is 1,660 with heavy oil, and 4,660 with light oil.

Taking the average ratios of $r$ as given before, the heating value of the mixture of air and gas drawn into the cylinder per cubic foot is, with producer gas 45 , with lighting gas 66 , with heavy oil 55 , and with light oil 114. If the clearance space is allowed for, and assuming 75 pounds compression, the figures are $37,48,37$, and 80 , respectively. A theoretically perfect engine requires $2,545 \mathrm{~B}$. T. U. per horse-powerhour, corresponding to a consumption of 17 cubic feet of producer gas, 3.9 cubic feet of lighting gas, 0.125 pound of heavy oil, 0.091 pound of light oil. If the efficiency of the gas producer is taken into account, minus 0.182 pound of anthracite or 0.212 pound of slack, as one pound of coal, the producer gives about 62 to 70 feet of gas.

The preceding formulas refer to ordinary 4-cycle single-acting engines. For engines with several cylinders, the power, fuel consumption, etc., should be taken for one cylinder alone, and if a double-acting cylinder, the power, fuel, etc., for one end.-Machinery.

The new steel process which is brought out in Europe and is to be controlled by Mr. Martin S. Kolman of New York has awakened considerable interest. Mr Kolman is preparing to make a demonstration of the process, which converts finished iron into steel, before a body of representatives from the lead.

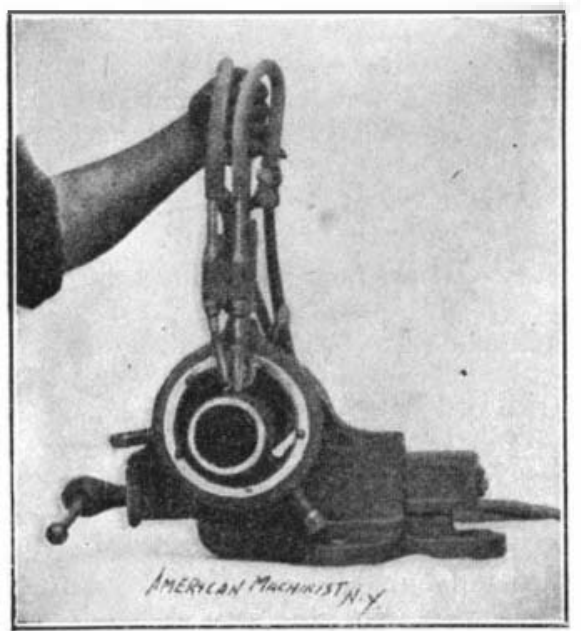

HIG. 12.-END VIEW OF PIPE-CU'ITING MIACHINE.

ing steel firms who are to be convoked for the purpose. A piece of iron can be given a coating of steel on the surface which can be as thin as an egg shell, or again can be of half an inch or an inch thickness according to the requirements. Using soft iron to make any kind of a shape, such as a razor blade, this can then be converted into very hard steel by the process, and it is claimed that such blades are equal to the best made. In this process the iron is simply treated with a chemical composition and is heated at the same time. The action of the composition serves to convert the iron into steel and gives it a temper at the same time, so that great bardness is the result. 